|| ISSN(online): 2589-8698 || ISSN(print): 2589-868X || International Journal of Medical and Biomedical Studies

Available Online at www.ijmbs.info

PubMed (National Library of Medicine ID: 101738825)

Index Copernicus Value 2017: 40.03

Volume 3, Issue 3; March: 2019; Page No.71-74

\title{
ASSESSMENT OF CERVICAL CYTOMORPHOLOGICAL CHANGES IN INFERTILE WOMEN
}

Garima Gupta ${ }^{1}$, Abhilasha Gupta ${ }^{2}$

${ }^{1}$ MBBS., SMS Medical College, Jaipur, Rajasthan

${ }^{2}$ DNB OBS \& GYNE, Senior Resident, Department of Obstetrics and Gynaecology, Kanwatia Hospital, SMS Medical College, Jaipur, Rajasthan

Article Info: Received 10 February 2019; Accepted 11 March. 2019

Cite this article as: Gupta, G., \& Gupta, A. (2019). ASSESSMENT OF CERVICAL CYTOMORPHOLOGICAL CHANGES IN INFERTILE WOMEN. International Journal of Medical and Biomedical Studies, 3(3).

DOI: https://doi.org/10.32553/ijmbs.v3i3.145

Address for Correspondence: Abhilasha Gupta, DNB OBS \& GYNE, Senior Resident, Department of Obstetrics and Gynaecology, Kanwatia Hospital, SMS Medical College, Jaipur, Rajasthan

Conflict of interest: No conflict of interest.

\section{Abstract}

Background: Infertility is a global problem, affecting approximately one-fifth of couples trying to conceive. With the incidence similar in most countries independent of the level of the country's development.

Methods: The hospital based prospective study was conducted on 50 women of reproductive age group who were in the follicular phase of their cycle and had primary and secondary infertility

Results: On pap smear $77.14 \%$ patients were present NILM, $15.71 \%$ patients were present ASC-US, 4.29\% patients were present inflammatory and $1.42 \%$ patients were present HSIL \& LSIL.

Conclusion: We observed that infertile patients may benefit from cervical cytological screening as they show a higher tendency for cervical cytological abnormalities. It is recommended to increase the awareness of the population about the importance of cancer cervix screening programs.

Keywords: pap smear, cancer cervix, ASC-US, HSIL, LSIL.

\section{Introduction:}

Infertility is a global problem, affecting approximately one-fifth of couples trying to conceive. ${ }^{1}$ with the incidence similar in most countries independent of the level of the country's development.

The incidence of infertility in men and women is almost identical. Infertility is exclusively a female problem in $30-40 \%$ of the cases and exclusively a male problem in $30-40 \%$ of the cases. Problems common to both partners are diagnosed in 10$15 \%$ of infertile couples.
Various factors may contribute to the infertility of males and females, including several types of microorganism, e.g., bacteria, fungi, viruses, and parasites. $^{2}$

A higher frequency of abnormal cervical smears is expected in subfertile women suffering from a tubal pathology ${ }^{3}$. The presumed increase in promiscuous, precarious sexual behaviour results in sexually active adolescents who are at risk of acquiring HPV and $C$. Trachomatis infections unaware of the fact that (tubal factor) subfertility and (the treatment of) severe cervical pathology could negatively affect family planning even many years following an infection. ${ }^{4}$ 


\section{Material and Methods}

The present study was conducted on 50 women of reproductive age group who were in the follicular phase of their cycle and had primary and secondary infertility

Inclusion Criteria

- Women of reproductive age group who were in the follicular phase of their cycle and had primary and secondary infertility prior to hormonal treatment (not taken hormonal treatment with in 3 month's).

- Who has given written and informed consent for study.

\section{Exclusion Criteria}

- Female with pelvic inflammatory disease at present.

- Female with diagnosed genital tract pathologies.

- Women who had started hormonal treatment with in 3 month's.

- Women who were on immunosuppressive drugs.

- Couple who use any type contraceptive method.

The inclusion and exclusion criteria were applied and patients who are eligible to participate and gave consent were thoroughly interviewed and investigated for etiology of infertilty.

A detailed history was taken regarding age, socioeconomic status, menstrual history, age of marriage and first coitus, duration of infertility, age of $1^{\text {st }}$ conception, obstetric history, personal history, spouse history, multiple sexual partner, STDs and health cheak up status including liquid base pap smear.

History was taken regarding previous treatment taken for infertility.

After enrolling the patient detailed history of both partner's was taken then complete physical examination including vitals parameter and systemic examination \& detailed gynaecological examination was carried out then routine investigation and complete work-up for infertility in both partner \& diagnostic procedure was carried out as required for infertility etiology.

After written informed concent pap smear taken by cervical broom, material on cervical broom was rinsed in $10-15 \mathrm{ml}$ of pap spin collection, a buffered methanol preservative solution in vial. Pap spin collection fluid along with collected material was send to laboratory for histopathological reporting.

\section{Observations}

Table 1: Age wise distribution

\begin{tabular}{|l|l|l|}
\hline Age group(Yrs) & No. of cases & Percentage \\
\hline $\mathbf{1 8 - 2 5}$ & 38 & $76.00 \%$ \\
\hline $\mathbf{2 6 - 3 0}$ & 10 & $20.00 \%$ \\
\hline $\mathbf{3 1 - 3 5}$ & 1 & $2.00 \%$ \\
\hline More than 35 & 1 & $2.00 \%$ \\
\hline Total & $\mathbf{5 0}$ & $\mathbf{1 0 0 . 0 0 \%}$ \\
\hline Mean age & $\mathbf{2 3 . 2 4 \pm 2 . 4 2}$ & \\
\hline
\end{tabular}

Mean age of patients were 23.24 \pm 2.42 Yrs. Maximum patients (76.00\%) were 18-25 Yrs age group. $82.00 \%$ patients were from urban area and $18.00 \%$ patients were from rural area. 
Table 2: Socio-economic status wise distribution

\begin{tabular}{|l|l|l|}
\hline Socio-economic status & No. of cases & Percentage \\
\hline Upper & 1 & $2.00 \%$ \\
\hline Upper-middle & 6 & $12.00 \%$ \\
\hline Lower-Middle & 21 & $42.00 \%$ \\
\hline Upper-lower & 11 & $22.00 \%$ \\
\hline Lower & 11 & $22.00 \%$ \\
\hline Total & 50 & $100 \%$ \\
\hline
\end{tabular}

Out of 50 cases $42.00 \%$ patients were lower middle class followed by $12.00 \%$ patients were upper middle class, $22.00 \%$ patients were lower class, $22.00 \%$ patients were upper-lower class and only $2.00 \%$ patients were upper class.

Table 3: Pap smear of cases wise distribution

\begin{tabular}{|l|l|l|}
\hline Pap smear & No. of cases & Percentage \\
\hline NILM & 38 & $76.00 \%$ \\
\hline LSIL & 1 & $2.00 \%$ \\
\hline HSIL & 1 & $2.00 \%$ \\
\hline ASC-US & 8 & $16.00 \%$ \\
\hline Inflammatory & 2 & $4.00 \%$ \\
\hline Total & 50 & $100.00 \%$ \\
\hline
\end{tabular}

On pap smear $76.00 \%$ patients were present NILM, $16.00 \%$ patients were present ASC-US, $4.00 \%$ patients were present inflammatory and $2.00 \%$ patients were present HSIL \& LSIL.

\section{Discussion}

Hospital based descriptive observational study conducted on 50 women of reproductive age group who were in the follicular phase of their cycle and had primary and secondary infertility prior to hormonal treatment (not taken hormonal treatment with in 3 month's) were included in this study.

Infertility is a serious problem to the couple and brings about family unhappiness and mental trauma and is a matter of financial burden. Screening by Pap smear enables for early detection of cervical cell abnormalities and prompt action. Consequently, we observe a significant decrease in the incidence of invasive cervical cancer. This study was designed to evaluate the results of cytology Pap smear test in infertile women.

Mean age of patients were $23.24 \pm 2.42$ Yrs. Maximum patients (76.00\%) were $18-25$ Yrs age group. $82.00 \%$ patients were from urban area and $18.00 \%$ patients were from rural area. Similar result were found by Sairem Mangolnganbi Chanu et $\mathrm{al}^{5}$ they observed that a total number of 151 patients underwent DHL out of which $88(58.28 \%)$ suffered from primary infertility and 63 (41.72\%) suffered from secondary infertility. The mean age of patients with primary infertility was $27.2 \pm 2.6$ years while the mean age of secondary infertility group were $32.4 \pm 2.2$ years.

Nasrin Jalilian et al ${ }^{6}$ was also found that mean (SD) age of the patients was 28.7 (6.3) years.

In our study on pap smear $76.00 \%$ patients were present NILM, $16.00 \%$ patients were present ASC-US, $4.00 \%$ patients were present inflammatory and $2.00 \%$ patients were present HSIL \& LSIL.Nasrin Jalilian et al ${ }^{6}$ was also found Cervical cytology was normal in 569 cases (97.8\%). There were 390 normal reports in 2007 
(97.5\%) and 179 normal cases (98.4\%) in 2011. In 10 cases (1.7\%), Pap smear result was unsatisfactory and only for 3 cases this was abnormal (0.5\%). Most cases of unsatisfactory result were reported in 2007 (9 cases out of 10 cases). Abnormal epithelial cells were ASCUS (one patient) and LSIL (two cases). The only ASCUS report was reported in 2011 and one LSIL was reported in the same year.

\section{Conclusion}

We observed that infertile patients may benefit from cervical cytological screening as they show a higher tendency for cervical cytological abnormalities. It is recommended to increase the awareness of the population about the importance of cancer cervix screening programs.

\section{References}

1. Schorge JO, Schaffer Jl, Halvorson LM. Williams Gynecology. New York, USA: The McGraw-Hill Companies; 2008.

2. Brown DR, Shew ML, Qadadri B, Neptune N, Vargas $M, T u$, Juliar BE, Breen TE and
Forte berry JD (2005) A longitudinal study of genital human papillomavirus infection in a cohort of closely followed adolescent women. J Infect Dis 191, 1 82-192.

3. Principles of prevention and surveillance of noncomunication disease Ministry of health and Medical educations; 2008.

4. Plante M, Goff MB, J Falk S. Patient information: Fertility preservation in women with early stage cervical cancer (Beyond the Basics). Apr 2, 2014. e Up-todate Terms of Use 02015 Up-to-date, Inc.

5. Chanu SM, Rudra Pal GS, Panda S, Santa Singh AS. Diagnostic hysterolaparoscopy for evaluation of infertility: Our experience in a tertiary Care Hospital. J Hum Reprod Sci 2018;11:19-23.

6. Jalilian N., Mahmoudzadeh R., Rezaei M. Comparison of the Elective and Emergent Ceasarean Section Complications in Kermanshah, Iran (2008-9). Life Sci J. 2013; 10(8s): 226-230. (ISSN: 1097-8135). 